\title{
Tissue Congestion
}

National Cancer Institute

\section{Source}

National Cancer Institute. Tissue Congestion. NCI Thesaurus. Code C82971.

A finding indicating the presence of increased blood volume in the vascular lumen. 